\title{
Endoscopic management of Zenker's diverticulum
}

\author{
Harpal S. Dhaliwal, Saroj K. Sinha, Rakesh Kochhar
}

\author{
Department of Gastroenterology, Post Graduate Institute of Medical Education and Research, Chandigarh, India
}

\begin{abstract}
Key words Cricopharyngeal diverticulum, endoscopic diverticulotomy, flexible endoscopic myotomy, pharyngo-esophageal diverticulum, Zenker's diverticulum
\end{abstract}

\section{Introduction}

Zenker's diverticulum (ZD), also known as cricopharyngeal or pharyngo-esophageal diverticulum, is an acquired outpouching of hypopharyngeal mucosa and submucosa in an area of junctional muscle weakness, known as Killian's triangle. It is an uncommon but highly treatable cause of mechanical dysphagia. We report two symptomatic cases of ZD managed by us using different flexible endoscopic techniques, along with an in depth review of the topic, with a special focus on minimally invasive flexible endoscopic techniques.

Address for correspondence:

Dr. Rakesh Kochhar, Department of Gastroenterology, Post Graduate

Institute of Medical Education and Research, Chandigarh - 160 012, India. E-mail: dr_kochhar@hotmail.com

\begin{tabular}{|l|c|}
\hline \multicolumn{2}{|c|}{ Access this article online } \\
\hline \multirow{2}{*}{$\begin{array}{l}\text { Website: } \\
\text { www.jdeonline.in }\end{array}$} & Quick Response Code \\
\hline DOI: & \\
10.4103/0976-5042.159235 & \\
\hline
\end{tabular}

\section{Case 1}

A 70-year-old male presented with a 5-year history of progressively worsening dysphagia to solids and liquids. $\mathrm{He}$ also had regurgitation of food and gradual loss of weight during this period. Barium swallow revealed a pharyngo-esophageal diverticulum, and upper endoscopy confirmed a wide ostium diverticulum arising proximal to the upper esophageal sphincter (UES), suggestive of ZD. Treatment options were discussed with the patient and accordingly, he underwent peroral flexible endoscopic myotomy, under conscious sedation with midazolam and pentazocine [Figure 1]. A nasogastric tube was put prior to the procedure for improved visualization. Under direct endoscopic vision, the septum was cut using a needle knife (Microknife ${ }^{\mathrm{TM}}$ XL, Boston Scientific, IN, USA) with a free-hand technique (Endocut I mode, effect 2, $60 \mathrm{~W}$,

This is an open access article distributed under the terms of the Creative Commons Attribution-NonCommercial-ShareAlike 3.0 License, which allows others to remix, tweak, and build upon the work non-commercially, as long as the author is credited and the new creations are licensed under the identical terms.

For reprints contact: reprints@medknow.com

How to cite this article: Dhaliwal HS, Sinha SK, Kochhar R. Endoscopic management of Zenker's diverticulum. J Dig Endosc 2015;6:45-54. 

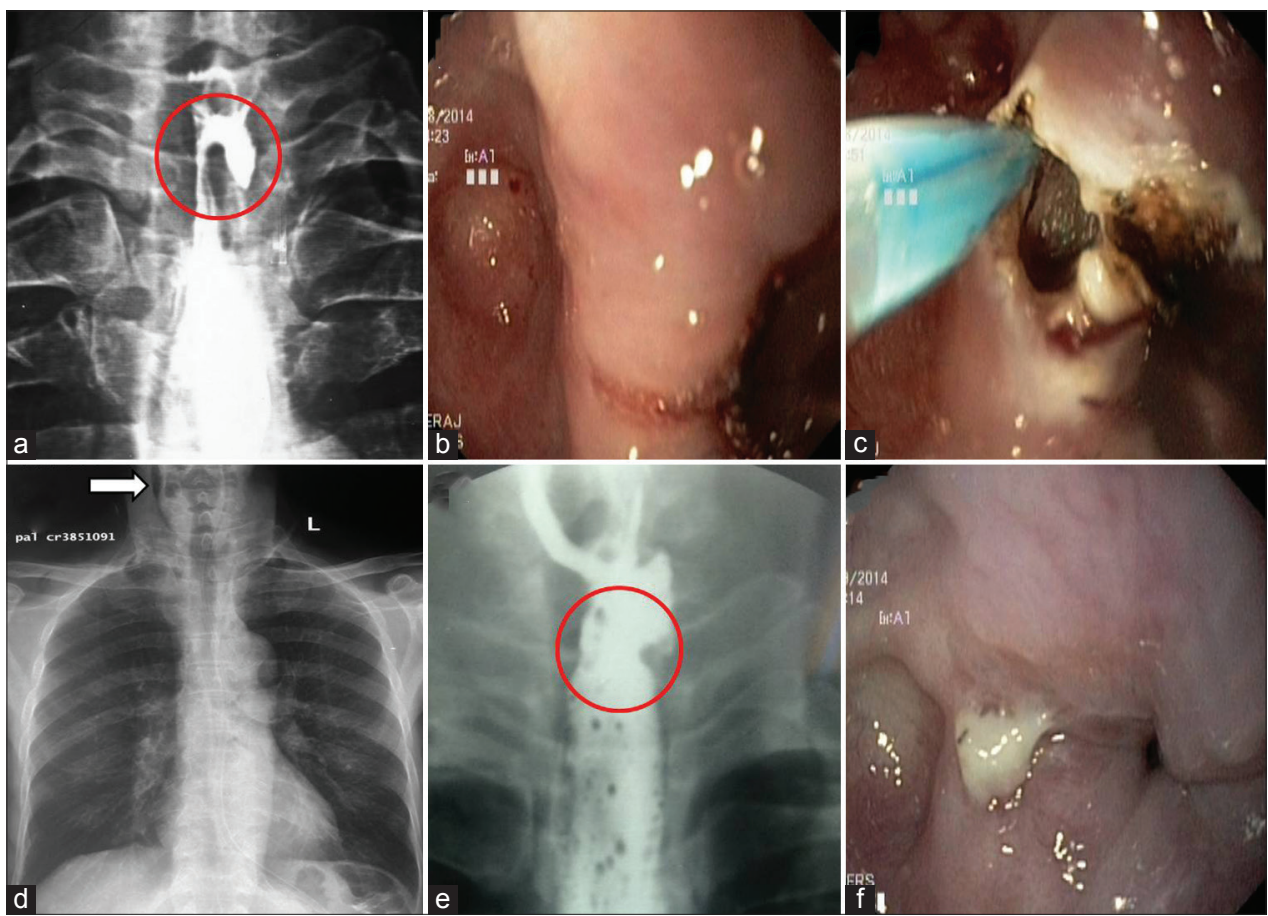

Figure 1: Flexible endoscopic myotomy with the needle knife in case 1. (a) Shows Zenker's diverticulum (ZD) on esophagogram. (b) Shows the endoscopic view with the ZD lying on the left side and esophageal lumen lying on the right side of the septum. (c) Shows the septum being cut with the needle knife. (d) Shows the development of cervical emphysema (white arrow) after the procedure, which resolved spontaneously. (e and f) are the views on the follow-up esophagogram and endoscopy, respectively, showing significant reduction in the height of the septum. The patient had resolution of all the ZD related symptoms after the procedure

VIO 300D; ERBE, Tubingen, Germany). The procedure was completed in $9 \mathrm{~min}$, without any complication. Postprocedure chest radiograph showed cervical emphysema. There was no chest pain or shortness of breath, and the emphysema resolved spontaneously. Oral feeding was resumed after $24 \mathrm{~h}$ and the patient was discharged in a satisfactory condition. A follow-up barium swallow showed a significant reduction in the height of cricopharyngeal bar [Figure 1]. His dysphagia and regurgitation completely resolved, and he is doing fine at 9 months of follow-up.

\section{Case 2}

A 56-year-old male presented with gradual onset dysphagia for 3 years. He also reported several episodes of choking with food getting stuck in his throat. His past history was significant for angioplasty for coronary artery disease, and he was on double antiplatelets. Barium swallow and upper endoscopy confirmed the presence of $\mathrm{ZD}$. After explaining the various therapeutic options, the patient opted for flexible endoscopic myotomy. Antiplatelets were stopped for a week and the procedure was performed under conscious sedation (midazolam and pentazocine) with a needle-knife. However, during the procedure, he had a significant ooze, which was controlled with argon plasma coagulation (APC). The rest of the procedure was completed with APC (forced coagulation mode, $50 \mathrm{~W}$, gas flow 1.8 L; ERBE, Tubingen, Germany) the next day [Figure 2]. Postprocedure chest radiograph was normal. On day 2, he was started on oral feeds and his symptoms had completely resolved. He had no complaints at 2 months of follow-up.

\section{Review on Zenker's Diverticulum}

Zenker's diverticulum is a posterior mucosal out-pouching from the area of relative hypopharyngeal weakness (Killian's triangle), formed as a result of pulsion forces operating in the pharynx, in the setting of discoordinated acts of swallowing. It is an uncommon disorder occurring predominantly in the elderly population, first reported by Ludlow in $1767 .^{[1]}$ However, the pathology of the condition was comprehensively described by Zenker and Von Ziemssen in their landmark paper on 34 patients in 1877. ${ }^{[2]}$ Over the last four decades, as knowledge advanced, a multitude of techniques was developed to successfully manage this condition with better outcomes and lesser complications.

\section{Pathophysiology}

As shown in Figure 3, gastrointestinal (GI) diverticulae can be either true or false diverticulae. True diverticulae contain all the layers of gut and are generally congenital. False diverticulae, generally acquired, are comprised of mucosa and submucosa and can be of pulsion or traction types. Pulsion type diverticulae are the result of push from inside, in response to an increased intraluminal pressure. Traction type diverticulae are formed by pull from outside; typical example being mid-esophageal diverticulae formed as a result of mediastinal scarring.

Zenker's diverticulum is an acquired pulsion-type of false diverticulum. It originates just proximal to the cricopharyngeus (CP) muscle, as a result of intraluminal 


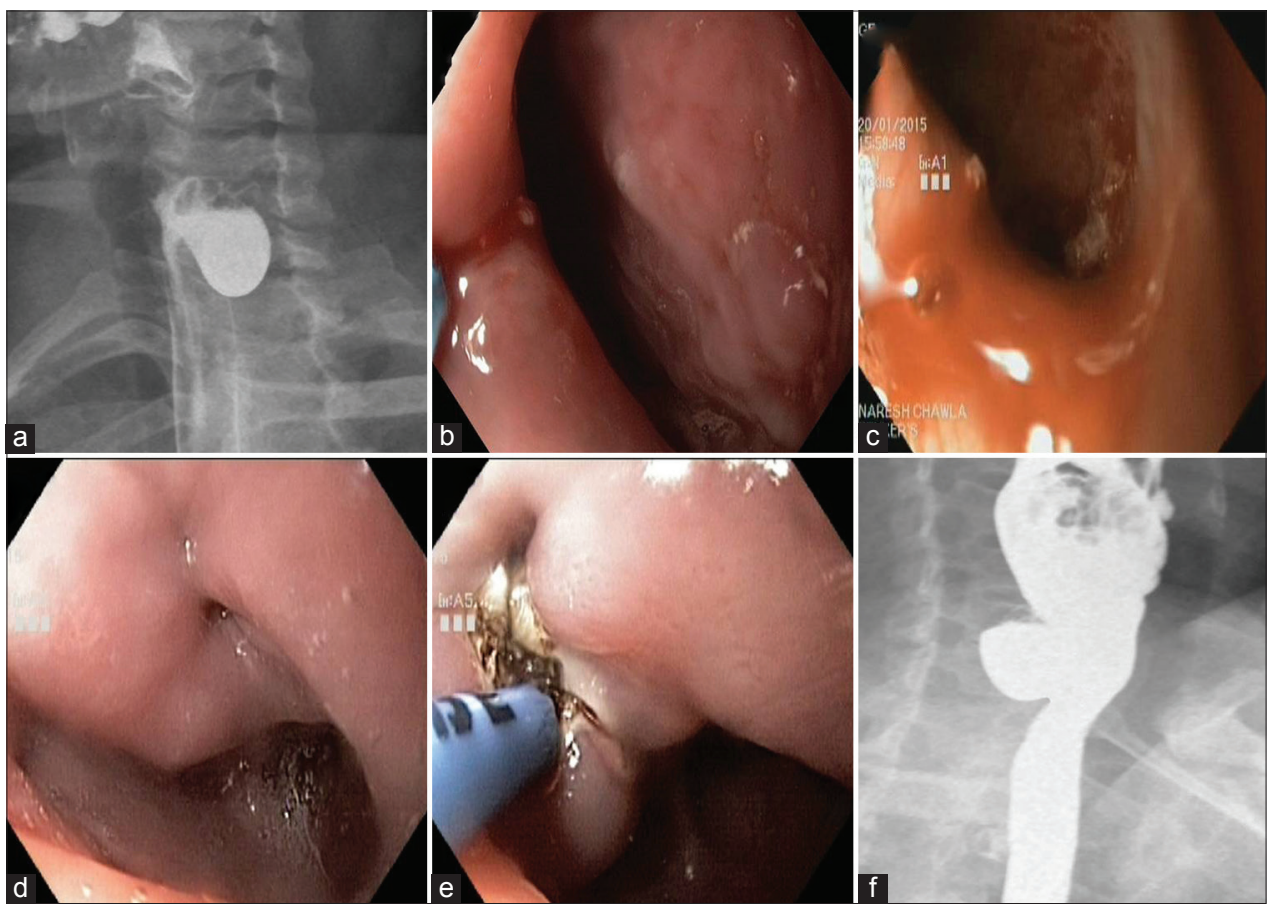

Figure 2: Flexible endoscopic myotomy in case 2. Esophagogram (a), shows Zenker's diverticulum. As the septum was cut with the needle knife (b), significant ooze developed (c) which was controlled with APC. Endoscopy next day showed incomplete myotomy (d) and the remaining part of the septum was cut with APC (e). Follow-up esophagogram showed a small residual part of the septum and the symptoms had settled after the procedure. Follow-up esophagogram ( $f$ ) showed a small residual part of the septum and the symptoms had settled after the procedure

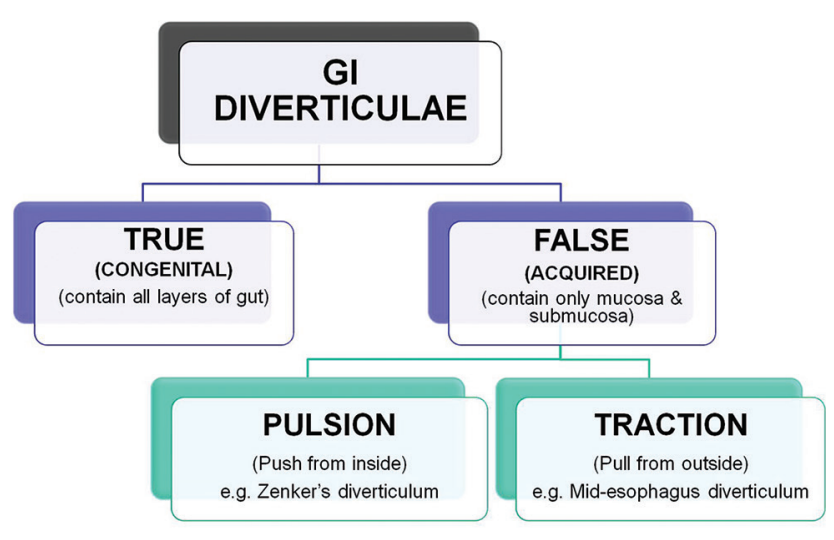

Figure 3: Classification of gastrointestinal diverticulae

forces pushing the mucosa and submucosa across the area of relative pharyngeal wall weakness called Killian's triangle. This triangle lies between the oblique fibers of inferior pharyngeal constrictor and circular CP muscle. However, the factors leading to increased intraluminal pressure are less clear. The most widely accepted theory is diminished compliance of UES with aging, leading to its incomplete opening in response to food bolus. ${ }^{[3]}$ Indirect evidence supporting this hypothesis is the replacement of muscle and normal connective tissue of UES with fibro-adipose tissue, with a subsequent increase in its stiffness. ${ }^{[4,5]}$ Furthermore, the age-related motor incoordination between pharyngeal contraction and UES relaxation during deglutition has been documented by a few investigators and could contribute to high pressures because of opposing forces acting on the food bolus. ${ }^{[6]} \mathrm{CP}$ spasm and gastroesophageal reflux disease (GERD) are other etiological factors which have been variably proposed. Whether GERD is the cause or effect of $\mathrm{ZD}$ is not clear and merits further research.

\section{Clinical features}

Zenker's diverticulum usually occurs in the seventh or eighth decade of life and is rarely diagnosed before the age of 40 years. ${ }^{[7]}$ The prevalence, based on western data, ranges between $0.01 \%$ and $0.11 \%$ and is twice as common in males. ${ }^{[7,8]}$ No prospective data are available from India, but the disease is certainly rare, compared to the west. It is unclear whether such epidemiological differences are solely accounted by the differences in longevity or additional pathogenetic mechanisms operate in high-risk populations.

A plethora of clinical manifestations have been described, the most notable among which is dysphagia, seen in $80-90 \%$ of patients with symptomatic ZD. Both intrinsic and extrinsic factors contribute to dysphagia. The incomplete opening of UES leads to dysphagia and preferential filling of the pouch. This increases the size of the pouch which then starts compressing the cervical esophagus extrinsically. Severe dysphagia may lead to weight loss and malnutrition. In severe cases, pulmonary symptoms (cough, aspiration, dyspnea, pneumonia, hoarseness of voice, etc.) may supervene. Some patients may complain of regurgitation of food and halitosis. Rare complications of ZD include ulceration, ${ }^{[9]}$ tracheoesophageal fistula, ${ }^{[10]}$ vocal cord paralysis, ${ }^{[10]}$ and 
fistulization to the prevertebral fascia leading to cervical osteomyelitis. ${ }^{[11]}$ Very rarely, a malignancy may develop in the diverticulum. ${ }^{[12]}$ This is thought to be due to chronic inflammation of the pouch lining over many years, secondary to food retention. ${ }^{[12]}$

Few peculiar manifestations of ZD have been documented in clinical practice. Inadvertent pushing of scope during esophageal intubation may lead to perforation across the diverticulum. ${ }^{[13]}$ Retained food within the diverticulum may transform into a bezoar. ${ }^{[14]}$ Pills might get lodged into the pouch, leading to a fall in the efficacy of medication. ${ }^{[15]}$ Video-capsule might get entrapped into the diverticulum. ${ }^{[16]}$ Hematemesis from a bleeding vessel within the ZD has been described and can be effectively managed endoscopically. ${ }^{[17]}$

Physical examination in these patients might reveal signs of malnutrition. A soft swelling on the left side of the neck may be present and may produce a gurgling sound on palpation (Boyce's sign or cervical borborygmi). The diagnosis suspected on the history and physical examination is confirmed on esophagography and endoscopy. Static images on esophagography may miss the diverticulum if it is small or imaged in only one plane; so dynamic imaging under continuous fluoroscopy is preferred. Figure 4 shows the typical appearances of $\mathrm{ZD}$ on gross examination, barium swallow, and endoscopic evaluation.

\section{Treatment}

Asymptomatic ZD found incidentally on upper endoscopy (performed for unrelated reasons) needs no treatment. Only symptomatic cases are treated, and a number of therapeutic options are available for the management of symptomatic ZD [Figure 5].

The treatment of ZD has evolved from open surgical approaches to less invasive transoral endoscopic techniques (rigid and flexible), with an associated fall in morbidity and mortality, along with an early recovery. The underlying principle of all the three techniques (open surgery, rigid and flexible endoscopic diverticulotomy) is two-fold: To disrupt the integrity of the diverticulum, and to divide the $\mathrm{CP}$ muscle (cricopharyngeal myotomy). The latter reduces the risk of postoperative fistula as well as future recurrences, by reducing the elevated hypopharyngeal pressures. ${ }^{[18]}$ As detailed below, both the objectives are fulfilled in a single go in the endoscopic techniques [Figure 6], while in open surgery, it requires two different steps.

\section{Open surgical approach}

The open surgical techniques essentially involve two steps: Tackling the diverticulum (by diverticulectomy, diverticulopexy or inversion) and addressing the underlying pathophysiology of cricopharyngeal dysfunction (by cricopharyngeal myotomy). ${ }^{[18]}$ An external neck incision is made anterior to the sternocleidomastoid muscle on the left side, given the propensity of the diverticulum to lateralize on this side. A myotomy is performed extending from lower $2 \mathrm{~cm}$ of inferior constrictor muscle, across the $\mathrm{CP}$ till the proximal esophagus (total length of myotomy being $4-5 \mathrm{~cm}$ ). ${ }^{[18]}$ Depending upon its size, the pouch can be tackled by three ways: Resection (diverticulectomy), suspension, and fixation

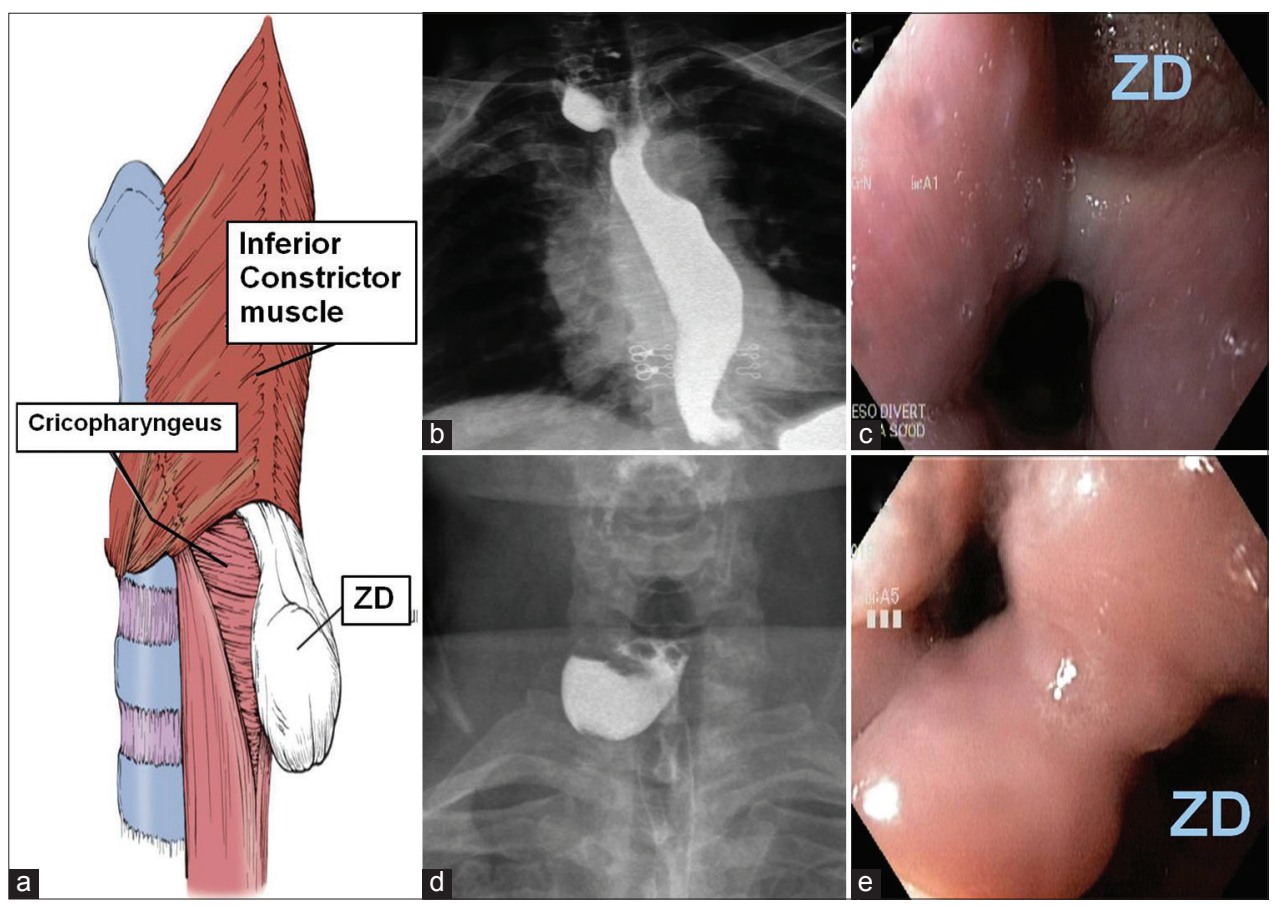

Figure 4: The different appearances of Zenker's diverticulum (ZD) on gross examination (a), barium swallow (b and d) and endoscopic evaluation ( $c$ and $e$ ). ( $b$ and $c$ ) Are the images from a patient with a small diverticulum while ( $d$ and $e$ ) shows a big diverticulum 


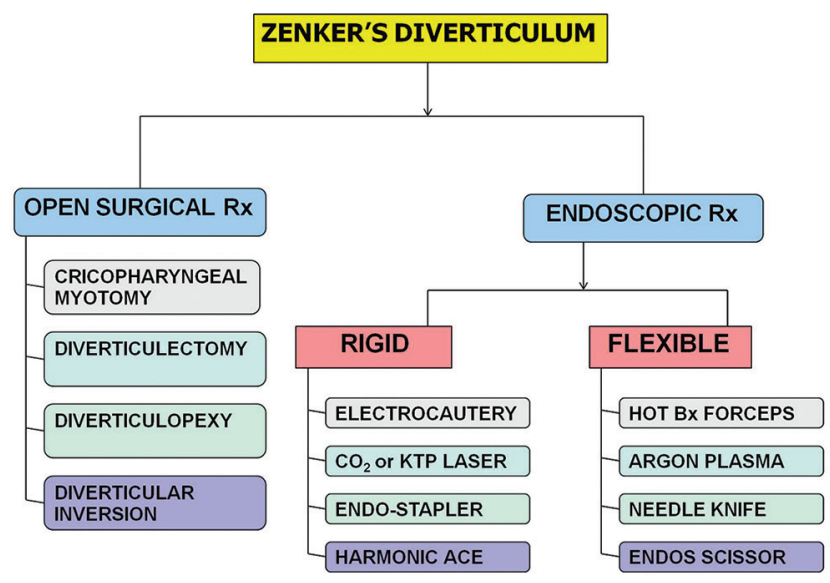

Figure 5: Various treatment modalities used for the management of Zenker's diverticulum

to the hypopharyngeal wall (diverticulopexy) or invagination into the esophagus itself (diverticular inversion). Larger pouches $(>5 \mathrm{~cm})$ are resected, and the defect is closed. Smaller pouches $(2-5 \mathrm{~cm})$ can be just suspended, and very small ones $(<2 \mathrm{~cm})$ can be invaginated or left as such. ${ }^{[18]}$

\section{Results}

With open surgery, symptoms resolve in $90-95 \%$ of patients and recurrence is rare. ${ }^{[18]}$ But the pharyngeal pouch surgery has long been associated with complications, partly because of the nature of the surgery itself and partly because of the predominant elderly patient population with underlying medical comorbidities. The mortality rate is up to $2.3 \% \cdot{ }^{[18]}$ The morbidity rate is $10.5 \%$, including recurrent laryngeal nerve injury in 3\%, leaks and perforations in 3\% and cervical infection in $2 \%$ of the subjects. Other complications of open surgery include local hematoma (1\%), respiratory infection $(0.3 \%)$, esophageal stenosis $(0.3 \%)$, and mediastinitis $(0.2 \%) .{ }^{[18]}$

\section{Transoral endoscopic techniques}

First described by Mosher in 1917 with rigid endoscopy, transoral endoscopic approaches are able to circumvent several complications of open surgery (like fistula, wound infection, and hematoma) because of the lack of external incision. They are also associated with less anesthetic and operative time, and an early recovery and hospital discharge. This not only reduces the hospital costs but also the risk of complications associated with prolonged hospital stay (hospital acquired infections, deep vein thrombosis, pulmonary thromboembolism, etc). These considerations become particularly important in $\mathrm{ZD}$, considering the predominantly frail elderly population afflicted by the disorder. Table 1 highlights the relative advantages and disadvantages of open surgical and endoscopic approaches.

The common goal of transoral endoscopic techniques is to divide the septum (along with the $\mathrm{CP}$ contained within it), separating the diverticulum from the esophageal lumen. This is

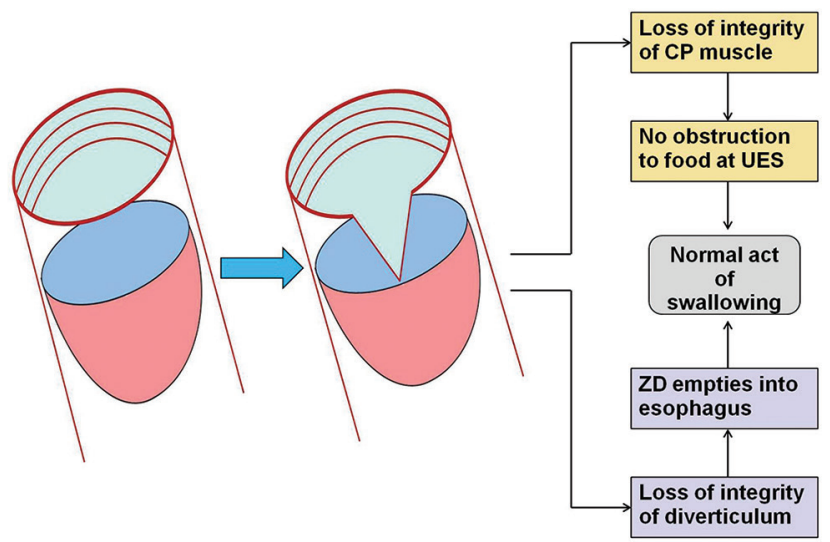

Figure 6: The principle of peroral endoscopic therapy of Zenker's diverticulum (ZD). Diminished compliance of cricopharyngeus (CP) with aging leads to incomplete opening of the UES during swallowing, elevated hypopharyngeal pressure and the formation of ZD. So, the treatment of $Z D$ requires 2 critical steps to ensure normal act of swallowing: Disruption of the integrity of diverticulum and addressal of the cricopharyngeal dysfunction. As the CP lies within the common septum, the septal division during peroral endoscopic therapy achieves both the objectives simultaneously: Diverticulotomy (resulting in free passage of diverticular contents into the esophagus) as well as cricopharyngeal myotomy (leading to correction of the underlying pathophysiology)

Table 1: Comparison of open surgical and endoscopic approach for the management of Zenker's diverticulum

\begin{tabular}{ll}
\hline Open surgical approach & Endoscopic approach \\
\hline An external incision on the & External incision is not \\
neck is given; it predisposes to & given, hence the associated
\end{tabular}

like fistula, wound infection

and hematoma formation

Cricopharyngeal dysfunction

and the diverticulum are

handled by 2 different steps

Longer procedural and

anaesthetic time

Morbidity and mortality more

Slow recovery and longer

hospital stay

Not suitable for elderly patients

with comorbidities

Resected pouch specimen can be assessed for carcinoma

Repeat surgery for recurrent disease difficult

Cricopharyngeal dysfunction and the diverticulum are treated in a single step (by septotomy) Shorter procedural and anaesthetic time Morbidity and mortality less Quick recovery and early hospital discharge

May not be suitable for small diverticulae

Histological assessment of the pouch not feasible

Repeat sessions of therapy can be easily given

essentially an "internal" cricopharyngeal myotomy and fulfills two objectives simultaneously [Figure 6]. The integrity of the diverticulum is lost, leading to free passage of its contents into the esophagus. Furthermore, the pathophysiology of $\mathrm{ZD}$ is reversed, and the severed $\mathrm{CP}$ no longer offers any resistance to the entry of food into the esophagus.

Transoral endoscopic techniques involve the use of either rigid or flexible endoscopy. The rigid endoscopic myotomy is performed by ENT surgeons under general anesthesia in the operation theater and requires hyper-extension of 
the neck. Flexible endoscopic myotomy is performed by gastroenterologists or surgical endoscopists in the endoscopy suite, under conscious sedation. The flexible endoscopic approach provides wider visual field with thinner and flexible endoscopes, which is especially useful in patients with poor neck extension and/or limited jaw retraction. Table 2 highlights the important differences between the rigid and flexible endoscopic myotomy.

\section{Rigid endoscopic myotomy}

The critical step in this technique is to visualize and expose the common septum separating the diverticulum from esophageal lumen. This is accomplished with a special rigid diverticuloscope, which is inserted perorally after hyper-extending the neck. Division of the septum can be accomplished by one of the various techniques: Electrocautery, $\mathrm{CO}_{2}$ laser, KTP/532 laser, stapler or Harmonic Ace. Classically, the rigid endoscopic myotomy was performed by electrocautery (Dohlman's technique). But the endoscopic stapler has become increasingly popular because of its advantages over other techniques. It simultaneously cuts and seals the edges of the wound with staples, with a very low rate of perforation and bleed. More-over, there is no risk of thermal damage to the recurrent laryngeal nerve.

\section{Results}

The efficacy of rigid endoscopy has been established in multiple studies with a median initial satisfactory outcome in $95 \%$ of subjects and recurrence or persistence rate of $5 \% \cdot{ }^{[19]}$ Although, the rigid endoscopic myotomy represents a significant advancement over the open surgical techniques, it can also be associated with a number of complications (cervical or mediastinal emphysema, perforation, dental injury, bleeding, esophageal mucosal tear, mediastinitis, esophageal stenosis, recurrent laryngeal nerve injury, neck abscess etc). These

\begin{tabular}{|c|c|}
\hline Rigid endoscopic myotomy & Flexible endoscopic myotomy \\
\hline $\begin{array}{l}\text { Relatively longer procedural } \\
\text { and anesthetic time }\end{array}$ & Shorter procedural time \\
\hline $\begin{array}{l}\text { Performed by ENT surgeons in } \\
\text { operation theaters }\end{array}$ & $\begin{array}{l}\text { Performed by gastroenterologists } \\
\text { or surgical endoscopists } \\
\text { in endoscopy suite }\end{array}$ \\
\hline $\begin{array}{l}\text { Neck hyperextension is a } \\
\text { pre-requisite }\end{array}$ & Neck hyperextension not required \\
\hline $\begin{array}{l}\text { Performed under general } \\
\text { anesthesia }\end{array}$ & $\begin{array}{l}\text { Can be performed under } \\
\text { conscious sedation }\end{array}$ \\
\hline $\begin{array}{l}\text { Not suitable for patients with } \\
\text { short neck, retrognathia, etc. }\end{array}$ & No anatomical contraindications \\
\hline $\begin{array}{l}\text { Less suitable for elderly } \\
\text { patients with comorbidities }\end{array}$ & $\begin{array}{l}\text { Best option for elderly patients } \\
\text { with comorbidities }\end{array}$ \\
\hline $\begin{array}{l}\text { Risk of perforation } \\
\text { less (especially with } \\
\text { endoscopic stapler) }\end{array}$ & $\begin{array}{l}\text { Perforation rates higher, especially } \\
\text { with free-hand techniques } \\
\text { (needle knife, hook knife) }\end{array}$ \\
\hline Overall morbidity higher (7-8\%) & Lower morbidity $(6 \%)$ \\
\hline Experience is more & Limited experience \\
\hline
\end{tabular}

ENT=Ear nose and throat, ZD=Zenker's diverticulum complications were reported in 7-8\% of patients in a systematic review of all the studies from 1990 to 2011, with a mortality of $0.2 \%{ }^{[18]}$ Another important drawback is the technical failure of getting adequate exposure of the septum, leading to conversion to open surgery in around $5 \%$ of the subjects. ${ }^{[18]}$ This technical failure occurs due to anatomical reasons (short neck, retrognathia, prominent teeth, large tongue, and cervical kyphosis), intra-operative esophageal mucosal injury and very small or large size of the diverticulum.

\section{Flexible endoscopic myotomy}

Flexible endoscopic techniques, first described as an effective therapy for ZD nearly two decades ago, have undergone a recent resurgence, in parallel with the developments in other areas of therapeutic GI endoscopy. Compared to the rigid endoscopy, flexible endoscopic myotomy offers similar efficacy and safety but with added advantages. In view of the flexibility and smaller diameter of the scope, neck hyperextension is not required and the procedure can be performed in patients who are otherwise unfit for rigid endoscopy because of anatomical factors (mentioned above). Furthermore, it can be performed under conscious sedation, as opposed to the requirement of general anesthesia in rigid endoscopy. The basic principle of both flexible and rigid endocopic myotomy is the same and is schematically highlighted in Figure 6.

The "Achilles heel" in endoluminal treatment of ZD is to ensure the optimal depth of the cut. ${ }^{[20]}$ Gauging precisely the extent of incision till the inferior-most fibers of $\mathrm{CP}$ muscle within the septum can be challenging. This roughly corresponds to $5-10 \mathrm{~mm}$ proximal to the base of diverticulum in the endoscopic view. ${ }^{[21]}$ As shown in Figure 7, the base of ZD generally lies deeper than the depth of the common septum and in this part, it hangs freely in the mediastinum, away from the esophageal wall. If the endoscopist "overshoots" beyond the thickness of $\mathrm{CP}$, the mediastinum will be opened up, leading to free perforation. If he "undershoots", there will a risk of recurrence of symptoms [Figure 7]. Since most endoscopists would prefer to stay on the safer side, it is not surprising that compared with open surgery, endoluminal therapy is associated with a higher risk of symptomatic recurrence. ${ }^{[20]}$

\section{Accessories for flexible endoscopic myotomy}

The accessories required for the procedure [Figure 8] are of two types: Those required for improving the endoscopic vision of the septum (nasogastric tube, soft diverticuloscope, transparent hood or cap) and those required for cutting the septum (needle-knife, hook-knife, monopolar forceps, APC, etc).

The soft diverticuloscope has been used in Europe to stabilize the septum, improve endoscopic vision and to further guide the instrument of incision. ${ }^{[7]}$ It is placed with its two stabilizing flanges within the esophageal lumen and within the diverticulum, leaving the septum in the center of the endoscopic field. Transparent hoods and caps attached 
to the endoscope, generally used in endoscopic mucosal resection, have also been used to improve the visualization. In a retrospective analysis of prospectively collected data on 39 consecutive patients undergoing flexible endoscopic diverticulotomy using either cap or diverticuloscope assistance, the latter was found to be significantly better. ${ }^{[22]}$ The procedure time was significantly longer with the cap than with diverticuloscope assistance $(P=0.002)$. Complications occurred in $9 / 28$ patients in the cap group and none in the diverticuloscope group $(P=0.04)$. The clinical remission rate was significantly higher after the diverticuloscope

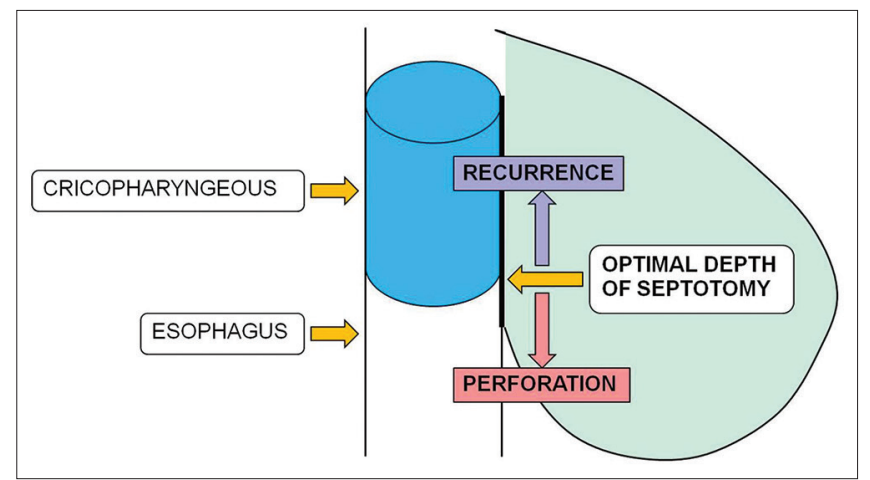

Figure 7: The optimal depth of septal incision in flexible endoscopic diverticulotomy is till the inferior-most fibers of cricopharyngeus (CP) muscle are cut, and loose areolar tissue is just encountered. Endoscopically, the precise limit of the cut is difficult to define accurately, and intraluminal treatment of Zenker's diverticulum is, in practical terms, a trade-off between 2 complications. "Overshooting" beyond the lowest part of CP muscle within the septum will lead to free perforation, while "undershooting" will spare a portion of the $\mathrm{CP}$, which may lead to symptomatic recurrence of the disease assisted procedure compared with the cap technique ( $82 \%$ vs. $29 \%, P=0.004$ ). Multivariate analysis showed that the diverticuloscope use was the only significant prognostic factor for the efficacy of the procedure (odds ratio $13.09,95 \%$ CI: $2.07 \pm 82.53) .{ }^{[22]}$

When the soft diverticuloscope is not used, the preprocedural nasogastric tube is generally placed and has several advantages. It improves the endoscopic view of the septum and supports it while being cut from the diverticular side. Since the septum is displaced away from the anterior wall of the esophagus by the tube, it prevents the accidental cauterization of the surrounding tissue. After the procedure, the tube ensures swallowing of saliva, in case significant local edema develops. It also ensures feeding if complications (mediastinal emphysema, perforation) develop after the procedure.

The optimal cutting technique remains elusive as randomized studies comparing them are lacking. In general, free-hand techniques (using needle-knife or hook-knife) are associated with more adverse events ${ }^{[22,23]}$ due to the poor control of cutting and lack of inbuilt hemostatic mechanisms within the accessory. Monopolar forceps might be better as they ensure "grasp and cut" rather than free-hand uncontrolled cut. But these forceps are not insulated, and there is a concern of inadvertent thermal injury to the surrounding tissue. Another forceps (endoscopic scissor or stag beetle knife) has been used with the similar cutting precision of the grasped tissue. ${ }^{[24]}$ In addition, it has inner cutting blades and outer insulated parts to protect the surrounding tissue. APC ensures simultaneous cutting and coagulation, so the risk of bleeding is low. But the
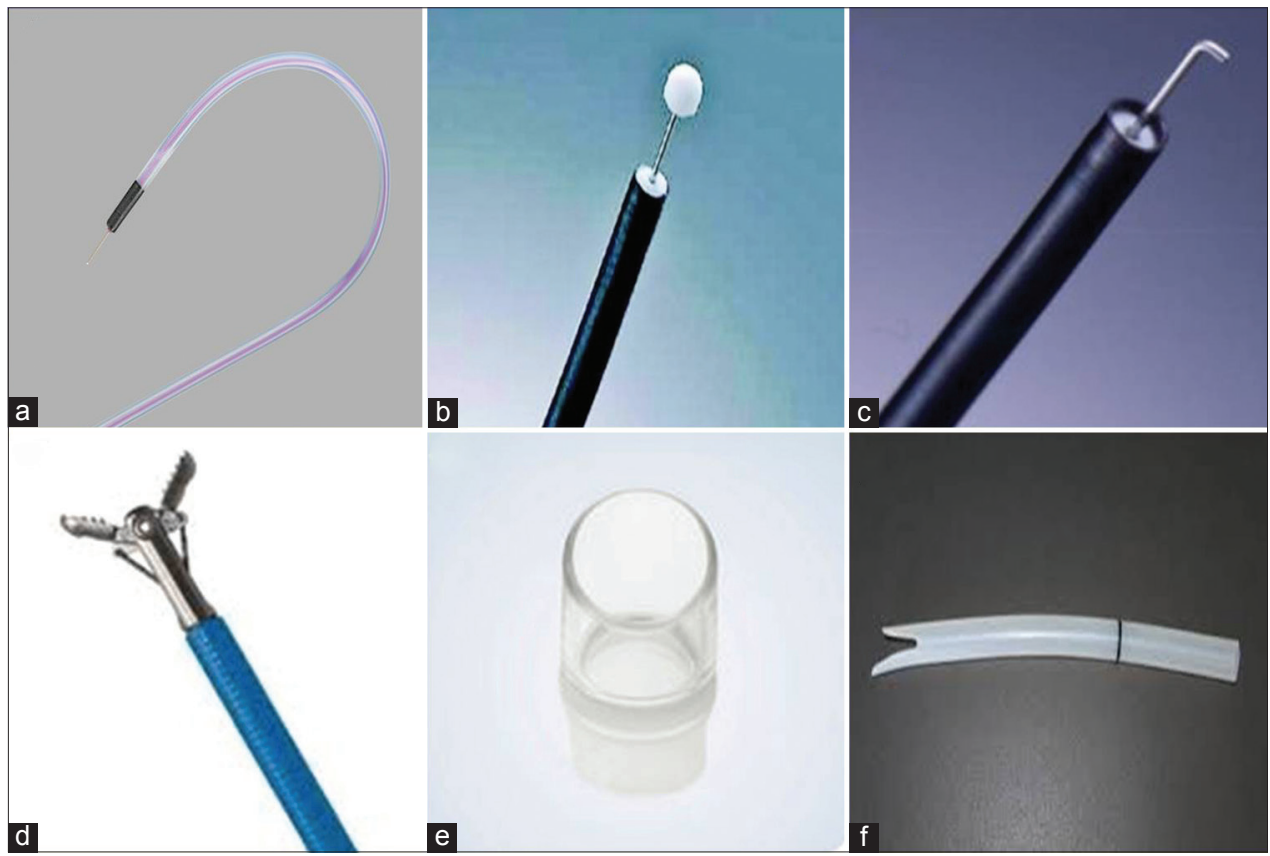

Figure 8: Various accessories used in flexible endoscopic myotomy. (a) shows standard needle knife (Wilson Cook), (b) shows insulated tip knife (Olympus), (c) shows hook knife (Olympus) and (d) shows monopolar forceps, all used for cutting the common septum. For improving the endoscopic visualization, transparent cap (e) and soft diverticuloscope (f) can be used 
number of sessions required with APC are more than with other accessories. ${ }^{[25,26]}$

\section{Details of flexible endoscopic myotomy and postprocedure management}

Flexible endotherapy is performed on an inpatient basis after an overnight fast. Routine antibiotic prophylaxis is not required. The throat is anesthetized with lidocaine spray and patient is placed in left decubitus position with neck slightly flexed. The procedure is generally performed under conscious sedation, and we prefer to give intravenous midazolam and pentazocine. We generally place nasogastric tube before the procedure, for the reasons mentioned earlier.

The cutting technique is chosen based on local endoscopic experience and preference. The septum is incised starting at the top in the midline, from the diverticular side toward the posterior wall of esophagus or vice-versa, depending on the individual anatomical situation. Intraprocedural bleed can be controlled with electrocautery (hot biopsy forceps, APC or if significant with epinephrine injection or endoclips). The septal division is continued till the lowermost fibers of cricopharyngeus muscle are cut, and loose areolar tissue is encountered. Care must be taken to stop at this point, lest the mediastinum will be opened [Figure 7]. Some endoscopists routinely place endoclip(s) at the base of septal incision to seal any microperforation into the mediastinum.

We prefer to give antibiotics for 3-5 days, after the procedure. The patient is closely watched for any evidence of perforation or infection. Chest radiograph is performed few hours after the procedure. Uncomplicated cervical emphysema represents microperforation and generally resolves spontaneously. However, the development of systemic inflammatory response syndrome with cervical or mediastinal emphysema is ominous and needs further evaluation with chest computed tomography to identify any free perforation and fluid collections.

In the absence of complications, the nasogastric tube is removed the next day, and oral feeding is resumed. A postprocedure esophagogram can be performed to demonstrate the disappearance/reduction of the diverticulum. But the presence or size of residual diverticulum does not correlate with symptomatic recurrence.

\section{Complications of flexible endoscopic myotomy}

The overall adverse event rate of all the series reported till 2013 is 6\% (range 0-38\%). ${ }^{[7]}$ Bleeding is the most common intra-procedural adverse event reported in $3 \%$ of subjects, although it is generally mild and can be easily controlled using various electrocautery techniques or endoclips. Postprocedural throat discomfort is nearly universal and can be treated with analgesics. Fever commonly occurs after APC and generally resolves within $24 \mathrm{~h}$. But high-grade fever persisting longer and associated with leukocytosis (even without signs of perforation or mediastinitis) should be treated with antibiotics. The most severe and clinically relevant adverse event is perforation and has been reported in $4 \%$ (range $0-27 \%$ ) in a recent review. ${ }^{[19]}$

\section{Outcomes of flexible endoscopic myotomy}

Several series have been published on flexible endoscopy using various cutting techniques [Table 3]. In most series, a clinical

\begin{tabular}{|c|c|c|c|c|c|c|c|c|c|}
\hline Author/year & $\begin{array}{c}\text { Number of } \\
\text { patients }\end{array}$ & $\begin{array}{l}\text { Median } \\
\text { age } \\
\text { (years) }\end{array}$ & $\begin{array}{l}\text { Accessories } \\
\text { used }\end{array}$ & Incision device & $\begin{array}{c}\text { Mean } \\
\text { number of } \\
\text { procedures }\end{array}$ & $\begin{array}{l}\text { Clinical } \\
\text { resolution } \\
\text { rate }(\%)\end{array}$ & $\begin{array}{c}\text { Adverse } \\
\text { event } \\
\text { rate (\%) }\end{array}$ & $\begin{array}{l}\text { Recurrence } \\
\text { rate } \\
(\%)\end{array}$ & $\begin{array}{l}\text { Follow-up } \\
\text { (months) }\end{array}$ \\
\hline $\begin{array}{l}\text { Ramchandani and } \\
\text { Nageshwar Reddy, 2013 } \\
\text { [24] }\end{array}$ & 3 & 79 & NGT, SD & Stag beetle knife & 1.0 & 100 & 0 & 0 & NA \\
\hline Huberty et al., 2013 27$]$ & 134 & 73 & SD & Needle-knife & 1.2 & NA & 2 & 15 & 43 \\
\hline Hondo et al., 2011[28] & 5 & 70 & SD & Harmonic scalpel & 1.2 & 100 & 0 & 0 & 1 \\
\hline Repici et al., 2010 29$]$ & 32 & 75 & NGT, hood & Hook knife & 1.1 & 92 & 3 & 13 & 24 \\
\hline Case and Baron, 2010[23] & 22 & 85 & NGT & Needle knife & 1.0 & 68 & 36 & 18 & 13 \\
\hline Al-Kadi et al., 2010[30] & 18 & 80 & NGT & Needle knife & 1.0 & 11 & 6 & 11 & 28 \\
\hline Tang et al., 2008 ${ }^{[31]}$ & 7 & 71 & NGT & Needle knife & 1.0 & 100 & 14 & NA & NA \\
\hline Manner et al., 2007 ${ }^{[32]}$ & 8 & 66 & NGT, cap & High power APC & 1.9 & NA & 38 & NA & NA \\
\hline Vogelsang et al., 2007 ${ }^{[33]}$ & 31 & 69 & NGT, cap & Needle knife & 1.4 & 84 & 23 & 35 & 26 \\
\hline Christiaens et al., 2007 ${ }^{[34]}$ & 21 & 78 & NGT, hood & Monopolar forceps & 1.1 & 100 & 5 & 10 & 23 \\
\hline Rabenstein et al., 2007[26] & 41 & 73 & NGT, cap & APC & 3.0 & 95 & 20 & 17 & 16 \\
\hline Costamagna et al., 2007 [22] & 11 & 70 & Cap & Needle knife & NA & 91 & 0 & 9 & 7 \\
\hline Costamagna et al., 2007[22] & 28 & 66 & NGT, SD & Needle knife & NA & 43 & 32 & 29 & 36 \\
\hline Evrard et al., 2003 ${ }^{[35]}$ & 31 & 78 & SD & Needle knife & 1.0 & 93 & 13 & 7 & 12 \\
\hline Sakai et al., 2001[36] & 10 & $67-87$ & Hood & Needle knife & 1.0 & 100 & 0 & 0 & NA \\
\hline Mulder, 1999[25] & 125 & 77 & NGT & APC & 1.8 & 100 & 19 & NA & NA \\
\hline Hashiba et al., 1999 ${ }^{[37]}$ & 47 & $58-81$ & NGT & Needle knife & 2.2 & 96 & NA & 0 & NA \\
\hline Ishioka et al., 1995 & 42 & 68 & NGT & Needle knife & 1.8 & 93 & 5 & 7 & 38 \\
\hline Mulder et al., 1995[39] & 20 & 82 & NGT & Forceps coagulation & 3.3 & 100 & 0 & 0 & 7 \\
\hline
\end{tabular}

NGT=Nasogastric tube, SD=Soft diverticuloscope, APC=Argon plasma coagulation, NA=Not available, ZD=Zenker's diverticulum 
resolution rate of $>90 \%$ using 1 or 2 treatment sessions have been documented. The rate of persistence or recurrence of symptoms is low $(<20 \%)$. Persistent or recurrent symptoms are easily amenable to repeat endoscopic therapy and the need for repeat therapy do not imply long-term therapeutic failure. ${ }^{[27]}$

One limitation of the current literature on flexible endoscopic diverticulotomy is the paucity of quality patient follow-up; the postprocedure follow-up is either not reported or relatively short. Future studies will have to demonstrate whether the long-term results are comparable to open surgery and rigid endoscopy. If so, the flexible endoscopic diverticulotomy would represent a significant step forward in the therapeutic armamentarium of ZD.

\section{Conclusions}

Treatment of ZD has greatly evolved over the last two decades. Endoscopic techniques clearly have an edge over the open surgical techniques in terms of less complications and early recovery. Both the rigid and flexible endoscopic myotomy can be performed with many techniques; more studies are needed to choose the best technique in both. Subsequently, the head-to-head comparative trials between the best flexible and rigid technique will clarify the overall optimal therapeutic strategy in these patients. Flexible endoscopic diverticulotomy is much simpler and less invasive than the rigid endoscopy. It is potentially a very promising technique for the high-risk elderly patients who, in particular, will benefit from a short procedure without general anesthesia and the need of neck hyperextension.

\section{Financial support and sponsorship \\ Nil.}

\section{Conflict of interest}

There are no conflict of interest.

\section{References}

1. Ludlow A. A case of obstructed deglutition from a preternatural dilatation of and bag formed in the pharynx. Medical observations and enquiries 1769;3:85-101.

2. Zenker FA, von Ziemssen H. Diseases of esophagus. Manual of special pathology and therapy 1877;7: 1-87.

3. Cook IJ, Gabb M, Panagopoulos V, Jamieson GG, Dodds WJ, Dent J, et al. Pharyngeal (Zenker's) diverticulum is a disorder of upper esophageal sphincter opening. Gastroenterology 1992;103:1229-35.

4. Zaninotto G, Costantini M, Boccù C, Anselmino M, Parenti A, Guidolin D, et al. Functional and morphological study of the cricopharyngeal muscle in patients with Zenker's diverticulum. Br J Surg 1996;83:1263-7.

5. Cook IJ, Blumbergs P, Cash K, Jamieson GG, Shearman DJ. Structural abnormalities of the cricopharyngeus muscle in patients with pharyngeal (Zenker's) diverticulum. J Gastroenterol Hepatol 1992;7:556-62.

6. van Overbeek JJ. Pathogenesis and methods of treatment of Zenker's diverticulum. Ann Otol Rhinol Laryngol 2003;112:583-93.

7. Law R, Katzka DA, Baron TH. Zenker's Diverticulum. Clin Gastroenterol Hepatol 2014;12:1773-82.

8. Watemberg S, Landau O, Avrahami R. Zenker's diverticulum: Reappraisal.
Am J Gastroenterol 1996;91:1494-8.

9. Shirazi KK, Daffner RH, Gaede JT. Ulcer occurring in Zenker's diverticulum. Gastrointest Radiol 1977;2:117-8.

10. Senders CW, Babin RW. Management of benign fistulae between Zenker's diverticulum and the trachea. Ann Otol Rhinol Laryngol 1983;92:349-52.

11. Frot-Martin B, Carlier RY, Morand-Blot V, Faye A, Bernard L, Vallée C. Zenker's diverticulum associated with multilevel cervical osteomyelitis. Spine (Phila Pa 1976) 2001;26:E193-7.

12. Bradley PJ, Kochaar A, Quraishi MS. Pharyngeal pouch carcinoma: Real or imaginary risks? Ann Otol Rhinol Laryngol 1999;108:1027-32.

13. Sobrino MA, Kozarek R, Low DE. Primary endoscopic management of esophageal perforation following transesophageal echocardiogram. J Clin Gastroenterol 2004;38:581-5.

14. Tsai CJ. Bezoar in a Zenker's diverticulum. Am J Gastroenterol 1994;89:944-6.

15. Seth R, Scharpf J. Medication ineffectiveness due to Zenker diverticulum in a compliant patient. Otolaryngol Head Neck Surg 2011;145:872-3.

16. Horiuchi A, Nakayama Y, Kajiyama M, Kato N, Kamijima T, Ichise Y, et al. Video capsule retention in a Zenker diverticulum. Case Rep Gastroenterol 2011;5:361-5.

17. Eaton J, Limsui D, Grover M. A man with dysphagia, aspiration, and hematemesis. Diagnosis: Hematemesis from a bleeding vessel in a large Zenker's diverticulum. Gastroenterology 2011;140:e11-2.

18. Yuan Y, Zhao YF, Hu Y, Chen LQ. Surgical treatment of Zenker's diverticulum. Dig Surg 2013;30:207-18.

19. Dzeletovic I, Ekbom DC, Baron TH. Flexible endoscopic and surgical management of Zenker's diverticulum. Expert Rev Gastroenterol Hepatol 2012;6:449-65.

20. Feussner H. Endoscopic therapy for Zenker diverticulum - The good and the bad. Endoscopy 2007;39:154-5.

21. Sakai P. Endoscopic treatment of Zenker's diverticulum. Gastrointest Endosc 2007;65:1054-5.

22. Costamagna G, Iacopini F, Tringali A, Marchese M, Spada C, Familiari P, et al. Flexible endoscopic Zenker's diverticulotomy: Cap-assisted technique vs. diverticuloscope-assisted technique. Endoscopy 2007;39:146-52.

23. Case DJ, Baron TH. Flexible endoscopic management of Zenker diverticulum: The Mayo Clinic experience. Mayo Clin Proc 2010;85:719-22.

24. Ramchandani M, Nageshwar Reddy D. New endoscopic "scissors" to treat Zenker's diverticulum (with video). Gastrointest Endosc 2013;78:645-8.

25. Mulder CJ. Zapping Zenker's diverticulum: Gastroscopic treatment. Can J Gastroenterol 1999;13:405-7.

26. Rabenstein T, May A, Michel J, Manner H, Pech O, Gossner L, et al. Argon plasma coagulation for flexible endoscopic Zenker's diverticulotomy. Endoscopy 2007;39:141-5.

27. Huberty V, El Bacha S, Blero D, Le Moine O, Hassid S, Devière J. Endoscopic treatment for Zenker's diverticulum: Long-term results (with video). Gastrointest Endosc 2013;77:701-7.

28. Hondo FY, Maluf-Filho F, Giordano-Nappi JH, Neves CZ, Cecconello I, Sakai P. Endoscopic treatment of Zenker's diverticulum by harmonic scalpel. Gastrointest Endosc 2011;74:666-71.

29. Repici A, Pagano N, Romeo F, Danese S, Arosio M, Rando G, et al. Endoscopic flexible treatment of Zenker's diverticulum: A modification of the needle-knife technique. Endoscopy 2010;42:532-5.

30. Al-Kadi AS, Maghrabi AA, Thomson D, Gillman LM, Dhalla S. Endoscopic treatment of Zenker diverticulum: Results of a 7-year experience. J Am Coll Surg 2010;211:239-43.

31. Tang SJ, Jazrawi SF, Chen E, Tang L, Myers LL. Flexible endoscopic clip-assisted Zenker's diverticulotomy: The first case series (with videos). Laryngoscope 2008;118:1199-205.

32. Manner H, May A, Rabenstein T, Pech O, Nachbar L, Enderle MD, et al. Prospective evaluation of a new high-power argon plasma coagulation system (hp-APC) in therapeutic gastrointestinal endoscopy. Scand J Gastroenterol 2007;42:397-405.

33. Vogelsang A, Preiss C, Neuhaus H, Schumacher B. Endotherapy of 
Zenker's diverticulum using the needle-knife technique: Long-term follow-up. Endoscopy 2007;39:131-6.

34. Christiaens P, De Roock W, Van Olmen A, Moons V, D'Haens G. Treatment of Zenker's diverticulum through a flexible endoscope with a transparent oblique-end hood attached to the tip and a monopolar forceps. Endoscopy 2007;39:137-40.

35. Evrard S, Le Moine O, Hassid S, Devière J. Zenker's diverticulum: A new endoscopic treatment with a soft diverticuloscope. Gastrointest Endosc 2003;58:116-20.

36. Sakai P, Ishioka S, Maluf-Filho F, Chaves D, Moura EG. Endoscopic treatment of Zenker's diverticulum with an oblique-end hood attached to the endoscope. Gastrointest Endosc 2001;54:760-3.

37. Hashiba K, de Paula AL, da Silva JG, Cappellanes CA, Moribe D, Castillo CF, et al. Endoscopic treatment of Zenker's diverticulum. Gastrointest Endosc 1999;49:93-7.

38. Ishioka S, Sakai P, Maluf Filho F, Melo JM. Endoscopic incision of Zenker's diverticula. Endoscopy 1995;27:433-7.

39. Mulder CJ, den Hartog G, Robijn RJ, Thies JE. Flexible endoscopic treatment of Zenker's diverticulum: A new approach. Endoscopy 1995;27:438-42. 